\title{
Estimation of the Tourism Benefits of Kakamega Forest, Kenya: A Travel Cost Approach
}

\author{
Mbuba David Mugambi ${ }^{1} \&$ John Irungu Mburu ${ }^{2}$ \\ ${ }^{1}$ Department of Environmental Sciences, Kenyatta University, Kenya \\ ${ }^{2}$ Department of Agricultural Economics, University of Nairobi, Kenya \\ Correspondence: Mbuba David Mugambi, Department of Environmental Sciences, Kenyatta University, Kenya. \\ E-mail: mugambis@yahoo.com
}

Received: August 28, 2012 Accepted: December 8, 2012 Online Published: December 15, 2012

doi:10.5539/enrr.v3n1p62 URL: http://dx.doi.org/10.5539/enrr.v3n1p62

\begin{abstract}
Policymakers in developing countries emphasize on short-term benefits of forest conversion over the long-term economic benefits such as recreational uses. This study used travel cost method to estimate the potential tourism or recreational benefits of two segments of Kakamega forest which are managed differently by Kenya Wildlife Services (KWS) and Kenya Forest Service (KFS). The empirical data used for this study was collected from past records on tourists' numbers and their country of origin from both management stations of the forest. The travel cost approach was then used to analyze the data. Results show that the forest generates considerable economic benefits, thereby justifying its continued conservation as a destination for tourists from Europe, USA and other parts of the world. Further, the results indicate that areas which are better conserved and protected (managed by KWS) have higher recreational benefits than those that are not well conserved (managed by KFS). This paper discusses Kakamega forest as an important tourism recreational site and justifies an increment in entrance fee for tourists.
\end{abstract}

Keywords: forest, recreation benefits, travel cost method, Kenya

\section{Introduction}

There has been an accelerated decline in forest cover in developing countries and hence reduction of the impacts forests have on climate change. Globally, it is estimated that about 1,011,000 $\mathrm{km}^{2}$ of forest was lost between year 2000-2005 (Hansen et al., 2010). Forest loss is caused mainly by human related factors which have led to a high rate of encroachment and degradation of forest resources. Moreover, market and policy failures are some of the underlying threats of conservation and protection of important global forest ecosystems in Kenya and other African countries with tropical rainforest (Mueller \& Mburu, 2009). Main justification for overlooking recreational benefits of forests is that they are usually public goods which are difficult to evaluate for their economic value.

Valuation of both tangible and intangible goods and services provided by forest ecosystems has become increasingly important at local, national and international levels. Lack of awareness of the total economic value of natural resources has contributed towards a narrow approach in formulation of policies geared towards conservation and protection of biodiversity. Lubbe (2001) reports that proper valuation of all the goods and services provided by forest can help policymakers to understand who benefits from the forest and who bears the management costs. Such benefits in case of Kakamega forest have not been estimated.

Kakamega forest is a famous tourist destination which is visited by both local and international tourists due to a high stock of biodiversity. The forest has two distinct parts which are differently managed by Kenya Wildlife Services and Kenya Forest Service (former Forest Department). Kenya Wildlife Services is in charge of Kakamega Forest National Reserve while Kenya Forest Service is in charge of Kakamega Forest Reserve. However, despite the forest being a key recreational site, it has been faced by threats like encroachment and degradation, hence affecting the biodiversity status of the forest.

The objective of this study was to apply the travel cost method to estimate and compare the recreational benefits of the two segments of Kakamega forest. This knowledge is important for policy makers in formulating sound biodiversity conservation policies. It would also facilitate harmonization of biodiversity conservation and forest 
management and also will help in economic gains for the country.

\section{Study Area and Methodology}

Kakamega forest is in the Western Kenya covering an area of about 240 sq. $\mathrm{Km}$ as the only remaining Eastern most remnant of the once Great Equatorial Rainforest that stretched from West Africa, through the Congo Basin and into East Africa. The forest lies in the Lake Victoria Basin; about $150 \mathrm{~km}$ west of the Great African Rift Valley, from which it is separated by highlands stretching from the Cherangani Hills in the North to the Mau Escarpment in the South (KIFCON, 1994). Adjacent to the forest in the East is the Nandi Escarpment which rises to an altitude of 2200 meters above the sea level. The forest is located to the West of the Nandi forests (North Nandi and South Nandi) which are highly deforested due to lack of proper management regimes (Map 1). The soils of Kakamega forest are moderately well drained clay loam, derived from Kavirondian, and Nyanzanian basement rock systems (Kigomo, 1987). It lies at an altitude of between $1500 \mathrm{~m}-1700 \mathrm{~m}$ with a fairly constant temperature with mean minimum range of 11 to $13^{\circ} \mathrm{C}$ and maximum range of $28^{\circ} \mathrm{C}$ to $32^{\circ} \mathrm{C}$. In addition, the forest has two distinct seasons, a wet season from March to October, and a dry season from November to February.

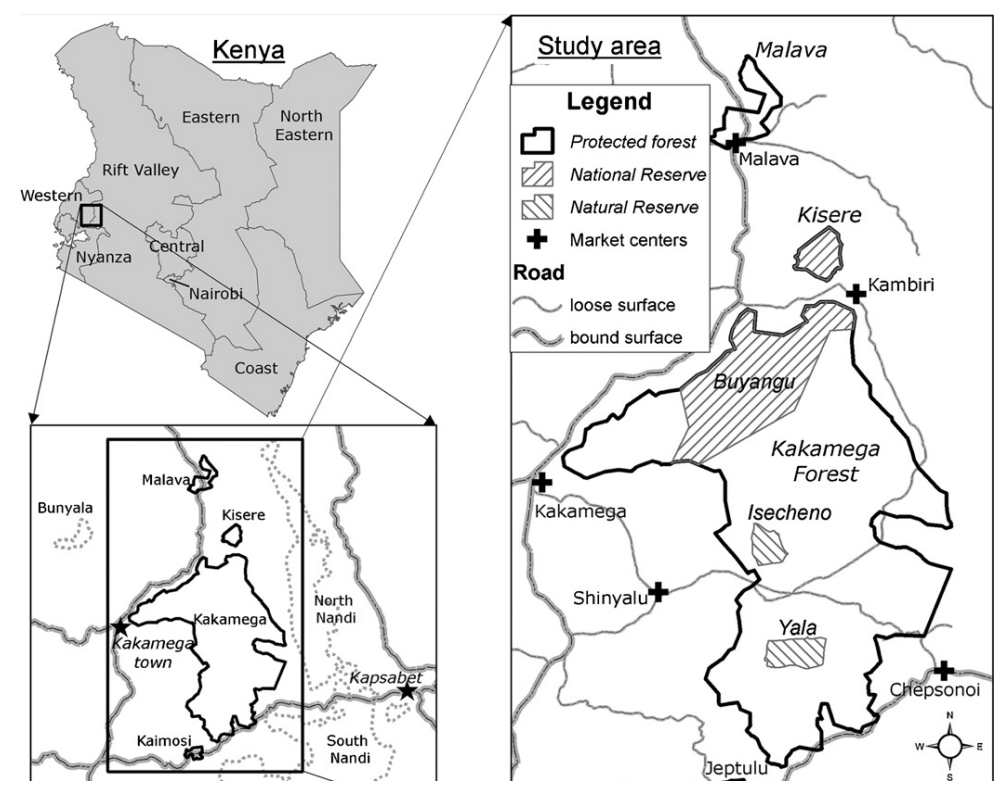

Map 1. Location of Kakmega forest (Mueller \& Mburu, 2009)

\subsection{Management Aspects of the Two Forest Sections}

The field study was conducted in the two segments of Kakamega forest (Kakamega Forest National Reserve and Kakamega Forest Reserve). Kakamega Forest National Reserve (often known as Buyangu Forest) is managed by Kenya Wildlife Service, whereby the forest is only accessed at a fee by tourists. On the other hand, Kakamega Forest Reserve is managed by Kenya Forest Service (formerly Forest Department) and it is accessed free of charge by both local and international tourists.

Kenya Wildlife Service generates revenue from the entry fees and camping charges. International tourists are usually charged 10 USD for both entrance fee and camping respectively per day, while local tourists pay 1.3 USD and 4 USD for entrance fee and camping. Kenya Forest Service, on other hand, generates revenue by charging guest houses (4 USD) and loyalties from grazing. Grazing usually attracts a small income. Although Kenya Forest Service charges no access fee, its section attracts fewer tourists than the KWS-managed area.

The variation in management of Kakamega forest has led to accelerated degradation and destruction of forest biodiversity, especially in the section under Kenya Forest Service. As the local communities can freely access this area, there is continuous extraction of non-timber forest products for local consumption and sale. The major concern is however grazing, as often livestock animals destroy indigenous grass and shrub species which have now become endemic. 


\subsection{Forest Biodiversity and Tourism Potential}

The forest is known for its richness in endemic avifaunal composition. As reported by Round-Turner (1994), 350 bird species and 400 butterfly species exist in this forest. The forest is also a home of several primates, reptiles and amphibians. The forest has been earmarked as an important global ecosystem and ranked by International Union for Conservation of Nature (IUCN) as one of the forest that should be given a high conservation priority in Kenya.

The current and future potential of tourism will be determined by sound management and protection of biodiversity in this particular forest. Although, the forest has remained a peripheral tourist destination in Kenya as result of inadequate marketing and accessibility, it is of interest to eco-tourists such as bird watchers, butterfly enthusiasts and researchers. This forest has great recreational benefits for the tourists from Europe, US, Australia, Far East and African countries.

\subsection{Data Collection}

The data used for this study was collected from Kenya Wildlife Services and Kenya Forest Service stations in Kakamega forest. The data collected included, tourists' numbers and their country of origin for three select years: 2002, 2003 and 2004. Although travel cost studies require data of 5-10 years to have valid conclusions, the current study used data for three years as this is what was available. These years were however 'normal tourism years' making it possible for derivation of some valid conclusions on tourism value of Kakamega forest. Besides collecting data on tourism from KWS and KFS records, key informant interviews were conducted with tourists who visited the forest during the time of field work in 2005.

The other useful information collected during the study was the average total amount for air fares for the three selected years which was obtained from travel agents. The visitors were zoned into concentric circles on the basis of travel cost from the country of origin to the site. There were seven (zones) units of observation. This information was useful in describing the relationship between the travel costs and number of visits from each zone.

\subsection{Valuation Methodology}

Travel cost methodology was used to estimate the recreational values. The travel cost method is widely used for non-market valuation in both developed and developing nations. Hanley \& Spash (1993) have identified this method for estimating economic benefits of recreation. For more detailed information on this method a reader can visit Hanley and Spash (1993) and Smith (1989). In Kenya, the method was used by Navrud and Mungatana (1994) to value the recreational benefits of wildlife viewing in Lake Nakuru National Park.

The travel cost approach indirectly places the value on non-market resources or public goods by either observing the real behaviour or using secondary information about visitation rate in a destination (Garrod \& Willis, 1999). Recent applications of the travel cost approach have incorporated careful modelling of on-site time in order to substantially improve estimates of the benefits of recreational visits, especially when on-site time is endogenous. This type of modelling often applies the Random Utility Model (RUM) (Berman \& Hong-Jin, 1999; Roasta \& Defrancesco, 2002)

The travel cost method uses the travel expenditure incurred in getting to the site as surrogate for the price by that visitor to the destination. This allows the estimation of a demand function as well as the consumer surplus. The method basically involves two basic steps (Read et al., 1999). The first step is to derive "trip generation function" (tgf) based on travel cost and other variables associated with the visitors. The second step is usually deriving the demand function for the visits to the sites from "tgf" using a hypothetical set of entry fees. This approach is based on the theory of demand, which assumes that there is an inverse relationship between the number of visits and entry fees.

\subsection{Factors Affecting Travel Costs to Kakamega Forest}

The travelers to Kakamega forest incur travel cost which comprise of transportation cost and opportunity cost of time (traveling time and time spent in the destination). Transport cost was calculated using the round trip airfare cost (Kramer et al., 1995) from the capital city of respondent's country of origin to the destination. We assumed the opportunity cost of traveling time to be zero (Ward \& Beal, 2002; Prabha et al., 2004) as it was assumed that tourists travel for leisure and recreation during the holidays when there is no loss of income. Tourists are likely to visit multiple sites in one trip, but we assume that the visitors had the sole purpose of visiting Kakamega forest. There is no other forest in Kenya which can be considered as a substitute site by the tourists as it is the only tropical rainforest in the country. All domestic tourists were put together as it was difficult to identify their towns of origin. Although the domestic tourists from far areas incur some substantial travel costs, these were assumed 
to be negligible when compared with those of other zones.

\section{Results}

The area surrounding Kakamega forest was divided into seven zones with increasing distances and travel cost from the point of departure of the visitor to forest. These zones included Kenya (domestic tourists), East Africa, other African countries, Asian continent, North and South America, and Australia and others. We assumed that the tourists from the same zone incurred an equal travel cost and had similar preferences while visiting the forest. The tourists from zone one were assumed to incur to no travel cost (Tables 1 and 2). Visitation rate (MVR) decreased with increase in distance from zone one. It is however worth to note that the MVR in zone 4 for both cases (Kenya Wildlife Services and Kenya Forest Service) did not follow this trend. This is due to the fact that most tourists in Kenya originate from this region since most of tourism promotion and marketing services had been targeting it.

Table 1. Average zonal visits and travel costs to Kenya Wildlife Services site of Kakamega forest

\begin{tabular}{ccccc}
\hline Zone & $\begin{array}{c}\text { Pop/1000 } \\
\text { (No of persons) }\end{array}$ & $\begin{array}{c}\text { Average travel cost for } \\
\text { three years (Tc) in Kshs. }\end{array}$ & Mean visits $\left(\mathrm{M}_{\mathrm{VR}}\right)$ \\
\hline 1 & Kenya & 19,453 & 0 & 880 \\
2 & East Africa & 13,609 & 49,000 & 305 \\
3 & Rest of Africa & 30,901 & 81,250 & 269 \\
4 & European countries & 410,766 & 140,360 & 1,950 \\
5 & Asian continent & 31,532 & 175,500 & 86 \\
6 & N and South America & 234,934 & 241,150 & 227 \\
7 & Australia and others & 43,024 & 243,400 & 28 \\
\hline
\end{tabular}

Table 2. Average zonal visits and travel costs Forest Department segment

\begin{tabular}{ccccc}
\hline Zone & & $\begin{array}{c}\text { Pop/1000 } \\
\text { (No of persons) }\end{array}$ & $\begin{array}{c}\text { Average travel cost for } \\
\text { three years }(\mathrm{Tc}) \text { in Kshs. }\end{array}$ & Mean visits $\left(\mathrm{M}_{\mathrm{VR}}\right)$ \\
\hline 1 & Kenya & 19,453 & 0 & 1440 \\
2 & East Africa & 13,609 & 49,000 & 254 \\
3 & Rest of Africa & 30,901 & 81,250 & 240 \\
4 & European countries & 410,766 & 140,360 & 839 \\
5 & Asian continent & 31,532 & 175,500 & 55 \\
6 & N and South America & 234,934 & 241,150 & 329 \\
7 & Australia and others & 43,024 & 243,400 & 38 \\
\hline
\end{tabular}

\subsection{Zonal Travel Cost Model Analysis for KWS and KFS- Managed Areas}

Based on the theory of demand, statistical regression analysis was carried out to establish the relationship between the number of visits $\left(\mathrm{M}_{\mathrm{VR}}\right)$ as the dependent variable and average travel cost $(\mathrm{Tc})$ as the independent variable. The output (Table 3) shows the results of fitting a curve to describe the relationship between the zonal travel costs and number of visits.

The coefficient for travel cost (Tc) is negative in both cases but significant at $5 \%$ level for Kenya Wildlife Services. The negative sign implies that as the travel cost increases, the total number of visits decreases. To establish the relationship between the number of visits and travel cost we used the estimated travel cost (Tc) coefficient from two regressions in (Table 3) to calculate the number of visits from each zone of origin as the total travel costs increased (effect of increasing the entrance fee on the travel cost). The increase in entrance fees reduced the number of visits from each zone. The entry fee was raised until increase in number of visits became zero. This was completed for each of the seven zones for both Kenya Wildlife Services and Kenya Forest Service. Finally, the total number of visits from all zones of origin is summed in relation to the entrance fee. 
Table 3. Regression analysis of zonal demand function for Kenya Wildlife Services and Forest Department segments

\begin{tabular}{ccc}
\hline & \multicolumn{2}{c}{ Estimated coefficients } \\
\cline { 2 - 3 } & Kenya Wildlife Services & Kenya Forest Service \\
\hline Constant & $898(2.965)^{* *}$ & $811(1.644)$ \\
Travel cost $(\mathrm{Tc})$ & $-0.003(-1.745)$ & $-0.002(-0.670)$ \\
Adj. $\mathrm{R}^{2}$ & 0.25 & 0.11 \\
Number of zones & 7 & 7 \\
\hline
\end{tabular}

Note: Dependent variable- total visits from each zone per year $\left(\mathrm{M}_{\mathrm{VR}}\right)$.

** Significant level at 5\% (2 tailed tests).

With the entrance fee (additional travel cost) and total visits from each zone the aggregate recreational benefits of the forest segments was estimated from the demand curves (Figures 1 and 2). This was arrived at by calculating the area of the shaded regions for both cases.

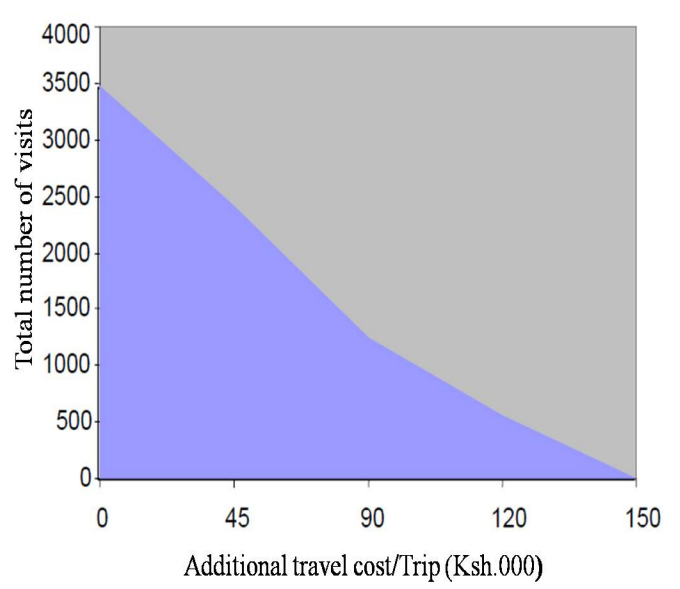

Figure 1. Relationship between additional travel cost (entrance fees) and total number of visits to Kenya Wildlife segment

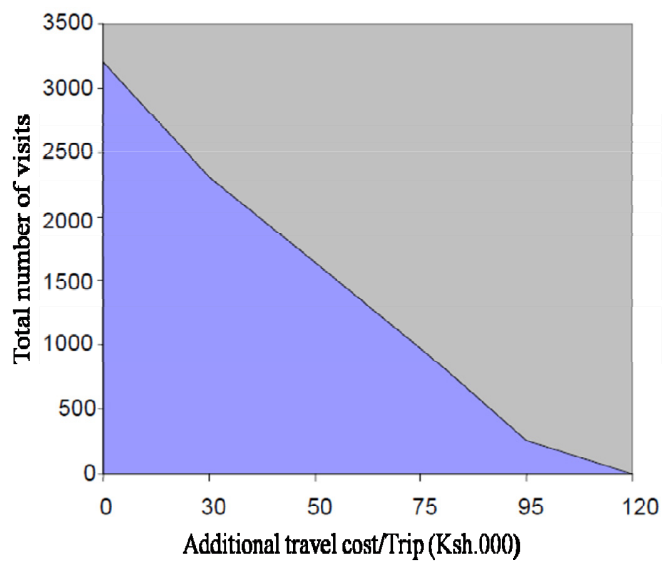

Figure 2. Relationship between additional travel cost (entrance fees) and total number of visits for forest department site

The estimated (generated from averages for three years) recreational benefits from both forest segments were US\$ 3.7 Million and US\$ 2.6 Million per year for Kenya Wildlife Services and Kenya Forest Service, respectively.

The results from the study indicated that the area managed by Kenya Wildlife Service (KWS) had a higher recreational potential benefits than that of the Kenya Forest Service. This is due to difference in management regimes applied by the two institutions, whereby the segment under KWS is mainly protected as tourist destination. The segment under Kenya Forest Service is managed for multiple uses like grazing, recreational use, source of medicinal plant among others. Despite our several assumptions in the analysis the magnitude of the result seems to be quite reasonable for policy consideration and implementation.

\section{Conclusion}

The findings demonstrate that the recreational value of a forest can be a substantial component of the total economic value. Further, the results show that conservation areas which are well conserved and protected may yield high economic benefits from tourism activities. These areas have high biodiversity hence attracting tourists with varied interests like game viewing, bird watching, nature walks, and study purposes among others. The results support strict conservation of natural forests for the purpose of generating income for states and their citizens and particularly local communities living adjacent to forests.

From the results of this paper, realization of huge economic benefits depends on effective management and protection of forest biodiversity. The degradation and encroachment of the forest from Kenya Forest Service 
segment could lead to substantial loss of biodiversity which eventually would be reflected in the reduced number of visitors. This implies that recreational benefits of the forest can be considered when persuading development partners and donors to make financial contributions for the conservation of the forest.

Due to the huge expenses incurred in conserving and protecting biodiversity in this forest, policy makers may wish to consider an introduction of a user access fee in the segment of the forest managed by the Kenya Forest Service and probably increase the present fee in the Kenya Wildlife service segment of the forest. Introduction of a user fee in the KFS-managed area should however go hand-in-hand with introduction of an effective management that will allow biodiversity improvement by halting forest degradation in the area.

\section{Acknowledgement}

The authors gratefully acknowledge the financial support from Kenyatta University, Biota East Africa (E13-subproject) and the German Catholic Academic Exchange Services (KAAD). Any errors and omissions are solely the responsibility of the authors.

\section{References}

Berman, M. D., \& Kim, H. J. (1999). Endogenous on-site time in the recreation demand model. Land Economics, 603-619. http://dx.doi.org/10.2307/3147069

Garrod, G., \& Willis, K. G. (1999). Economic Valuation of the Environment. Massachusetts, UK. Edward Elgar Publishing Ltd.

Hanley, N., \& Spash, C. (1993). Cost-Benefit Analysis and Environment. London: Edward Elgar Publishing Ltd.

KIFCON. (1994). Kakamega Forest: The Official Guide: Kenya Indigenous Forest Conserving Programme. Nairobi, Kenya, p. 67.

Kigomo, B. N. (1987). Some Observation on Vegetation Regeneration in the Kakamega and South Nandi Forest, Kenya. East Africa Agriculture and Forestry Journal, 52, 184-195.

Kramer, R. A, Sharma, N., \& Munasighe, M. (1995). Valuing Tropical Forests: Methodology and Case Study of Madagascar. World Bank Environment Paper No. 13. Washington DC, USA.

Lubbe, M. V. (2001). The Art of Forest Valuation: Methods to Value Goods and Services and What else? National Reference for Nature Management. Wageningen Netherlands.

Matthew, C. H., Stephen, V. S., \& Peter, V. P. (2010). Quantification of global gross forest cover loss. Proceedings of the National Academy of Sciences, 107(19), 8650-8655. http://dx.doi.org/10.1073/pnas.0912668107

Müller, D., \& Mburu, J. (2009). Forecasting hotspots of forest clearing in Kakamega Forest, Western Kenya. Forest Ecology and Management, 257(3), 968-977. http://dx.doi.org/10.1016/j.foreco.2008.10.032

Navrud, S. Å., \& Mungatana E., (1994). Environmental valuation in developing countries: the recreational value of wildlife viewing. Ecological Economics, $11(2), \quad$ 135-151. http://dx.doi.org/10.1016/0921-8009(94)90024-8

Prabha, P., John, \& Jack, S. (2004). Using the Travel Cost Method to Estimate the Value of Special Events in Regional Areas. Melbourne, Australia.

Read, M., Sinden, Branson, J. A., \& Stargess, N. (1999). Recreational Use Values for Victoria's Park. 43rd Annual Conference of Australian Agricultural Resource Economics Society. Christchurch, New Zealand.

Rosato, P., \& Defrancesco, E. (2002). Individual Travel Cost Method and Flow Fixed Costs. FEEM Working Paper Series. Retrieved from http://papers.ssrn.com/sol3/papers.cfm?

Round- Turner, D. (1994). Kakamega Forest: The Official Guide. Nairobi, Kenya.

Smith, V. K (1989). Taking stock of progress with travel cost recreation demand methods: Theory and Implementation. Marine Resource economics, 6, 279- 310.

Ward, F., \& Beal, D. (2000). Valuing Nature with Travel Cost Models: A Manual. Edward Elgar, and Cheltenham, UK. 